$\underline{\text { Case Reports }}$

\title{
Hypophosphatemic Osteomalacia Associated with Tenofovir: a Multidisciplinary Approach is Required.
}

Giuseppe Vittorio L. De Socio, ${ }^{1}$ Gianluigi Fabbriciani, ${ }^{2}$ Marco Massarotti, ${ }^{2}$ Salvatore Messina, ${ }^{3}$ Enisia Cecchini ${ }^{1}$ and Bianca Marasini. ${ }^{4}$

${ }^{1}$ Unit of Infectious Diseases, Hospital "Santa Maria della Misericordia", Perugia, Italy

${ }^{2}$ Rheumatology Unit, IRCCS Humanitas Clinical Institute, Rozzano (Milano), Italy

${ }^{3}$ Nuclear Medicine 1, Hospital "Santa Maria della Misericordia", Perugia, Italy

${ }^{4}$ Rheumatology Unit, IRCCS Humanitas Clinical Institute, Rozzano (Milano), University of Milano, Italy

Correspondence to: Giuseppe Vittorio L. De Socio, M.D. Unit of Infectious Diseases, Hospital "Santa Maria della Misericordia". Piazzale Menghini,1 - 06129 Perugia (PG), Italy. Phone: +390755784319 - Fax: +390755784346

E-mail: giuseppedesocio@yahoo.it

Competing interests: The authors have declared that no competing interests exist.

Published: May 4, 2012

Received: January 19, 2012

Accepted: March 28, 2012

Citation: Mediterr J Hematol Infect Dis 2012, 4(1): e2012025, DOI: 10.4084/MJHID.2012.025

This article is available from: http://www.mjhid.org/article/view/9950

This is an Open Access article distributed under the terms of the Creative Commons Attribution License (http://creativecommons.org/licenses/by/2.0), which permits unrestricted use, distribution, and reproduction in any medium, provided the original work is properly cited.

Abstract. Tenofovir is widely used as first-line treatment of HIV infection, although its use is sometimes complicated by a reversible proximal renal tubulopathy.

We report the case of a 45-year-old woman with chronic HIV infection and personality disorder, who after 12 months of tenofovir, complained of fatigue, diffuse bone pain and gait disturbances. The elevated level of alkaline phosphatase, hypophosphatemia and inappropriate phosphaturia suggested the diagnosis of hypophosphatemic osteomalacia secondary to proximal renal tubulopathy. A dual-energy x-ray absorptiometry showed a bone mineral density below the expected range for age (lumbar spine $Z$-score -3.3 , femoral neck $Z$-score -2.1 ). A whole body ${ }^{99 m}$ Tcmethylene diphosphonate bone scan showed multiple areas of increased focal activity in the lumbar and thoracic spine and in sacroiliac and hip joints consistent with pseudo-fractures. Two months after tenofovir discontinuation and administration of vitamin $D$ and phosphate, osteomalaciarelated symptoms disappeared. Eleven months later, bone and mineral metabolism data were normal and bone scintigraphy did not show any pathological findings.

This report highlights the importance of considering the diagnosis of osteomalacia in patients treated with tenofovir and emphasizes the need for monitoring alkaline phosphatase, blood and urinary phosphate and creatinine, especially in patients with risk factors for bone disease.

Introduction. A number of bone diseases, including osteoporosis, ${ }^{1}$ osteonecrosis ${ }^{2}$ and even osteomalacia (OM), although rare, ${ }^{3,4}$ have been described in human immunodeficiency virus (HIV)-positive patients, and considered due to HIV infection itself, to HIV-related co-morbiditiers as well as to drug toxicity. Tenofovir 
disoproxil fumarate (TDF) (Viread ${ }^{\circledR}$ ) is the oral prodrug of TDF, an adenine analog reverse transcriptase inhibitor, widely prescribed in combination with antiretroviral therapy (ART), because of convenient dosage and a good safety profile. However, there is concern about its potential nephrotoxicity. TDF use, in fact, has been associated with proximal renal tubulopathy (PRT) and loss in bone mineral density (BMD) ${ }^{5,6}$ Minor proximal renal tubule abnormalities leading to phosphate wasting and 1- $\alpha$-hydroxylation defects of vitamin $\mathrm{D}$ with subsequent clinical $\mathrm{OM}$, have been found in $1.6 \%$ to $22 \%$ of TDF-treated patients. ${ }^{7,8}$

TDF toxicity may be increased in HIV-infected subjects because of their accelerated biological aging, ${ }^{9}$ difficult to treat co-morbidities, including psychiatric disorders ${ }^{10,11}$ and complex drug regimens. ${ }^{12}$ The case of TDF-induced OM in a patient with chronic HIV infection here reported might provide an opportunity for an important "teaching point" In prospective controlled clinical trials, in fact, a specific, "ad hoc" investigation of bone TDF toxicity is lacking, and the only available informations are coming from case reports and observational case series.

Case Report. A 45-year-old HIV-infected woman came to our observation in March 2010 with a 4-6month history of fatigue, severe pain in the hip joints, rib cage, dorsal and lumbosacral spine, causing gait instability. She after 12 months of ART including TDF, complained initial gait disturbances. Her HIV-1 infection was probably due to unprotected sexual contacts prior to 1988. She also had chronic HCVrelated hepatitis (genotype 1b) and borderline personality disorder. Her family history was unremarkable. In the past, she had been treated with several antiretroviral therapies, although not strictly followed because of her psychiatric disorder. Since September 2008, once admitted in a non-profit Residential Care Facility, she was receiving regular ART. At the last follow-up, HIV-1 RNA count was almost undetectable levels $(<20$ copies/mL) and CD4 cell count was $322 / \mathrm{mm}^{3}$, while in September 2008 HIV-1 RNA was 510 copies/mL and the CD4 cell

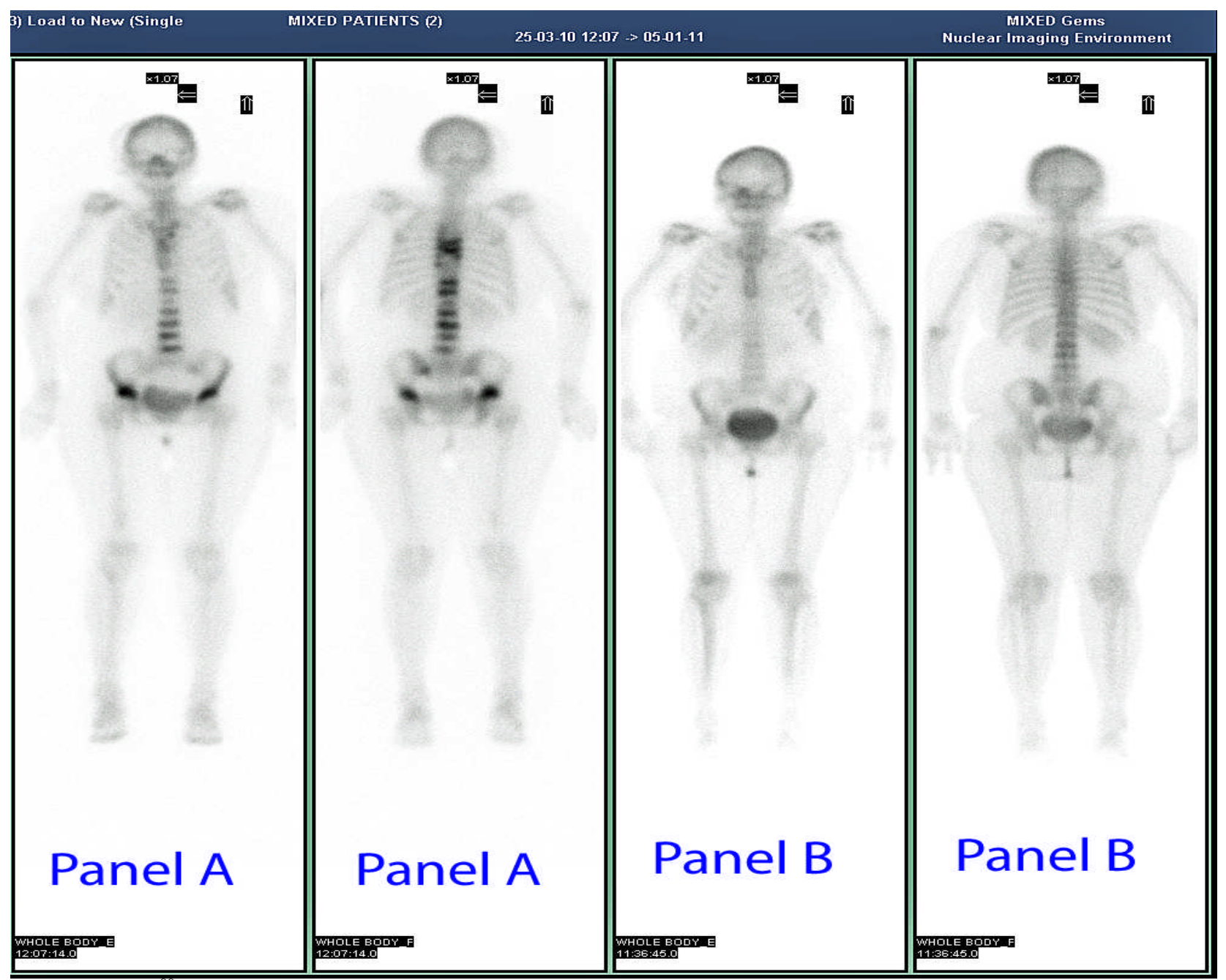

Figure 1. Whole body ${ }^{99 \mathrm{~m}} \mathrm{Tc}-\mathrm{MDP}$ bone scintigraphy. Panel A (anterior and posterior), at clinical presentation: increased focal uptake in the lumbar/thoracic spine, sacroiliac regions and hip joints consistent with multiple pseudofractures. Panel B (anterior and posterior), eight months after TDF discontinuation: absence of increased uptake. 


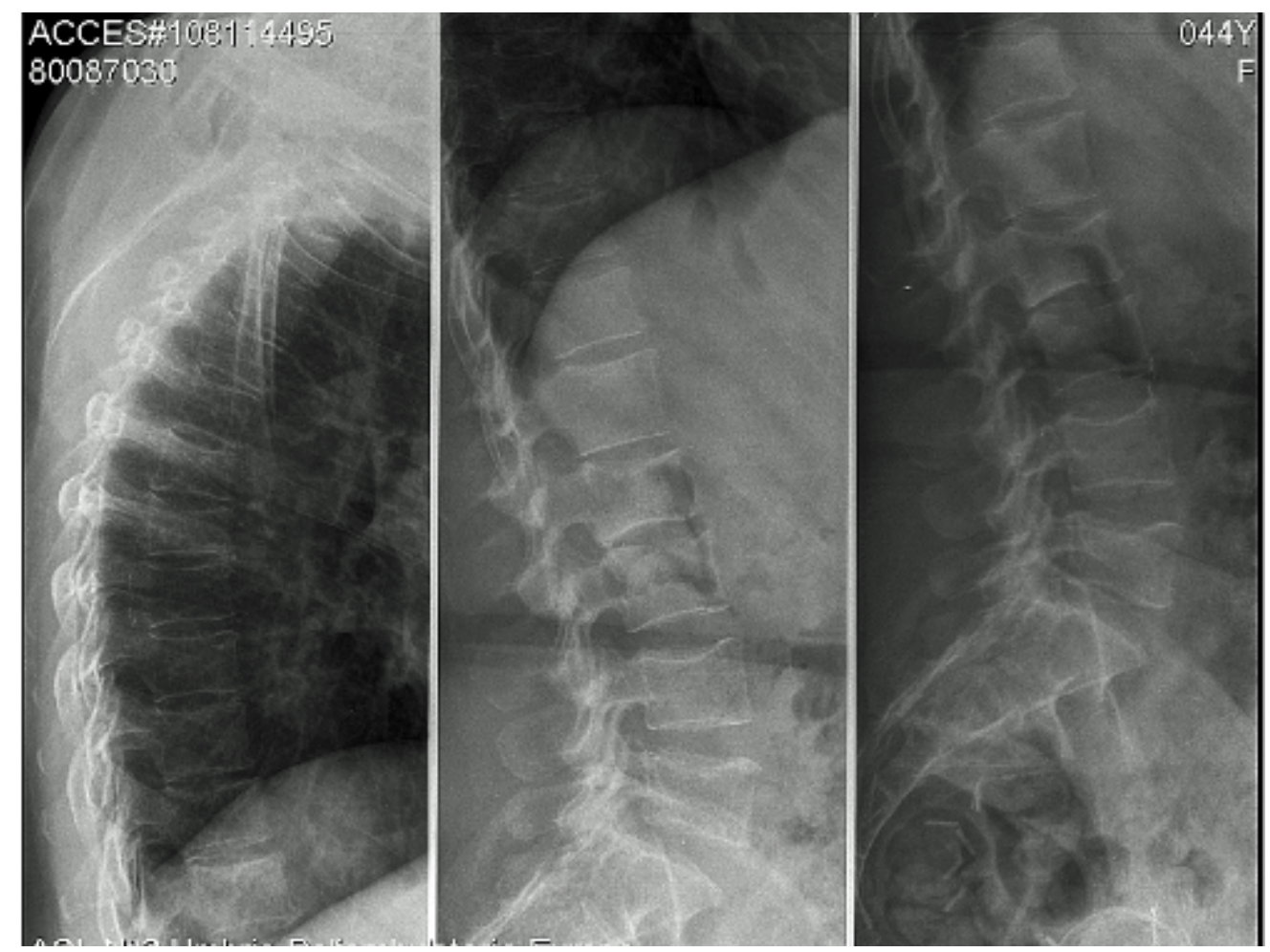

Figure 2. Dorso-lumbosacral spine X-ray: fracture deformities of D/7and of the bodies of L/2-4, in a general aspect of diffuse osteopenia.

count $298 / \mathrm{mm}^{3}$. When first visited by us (on March 2010), her treatment included zidovudine $300 \mathrm{mg}$ every 12h, TDF $245 \mathrm{mg}$ daily, atazanavir $300 \mathrm{mg}$ daily boosted by ritonavir $100 \mathrm{mg}$ daily, risperidone 3 $\mathrm{mg}$ b.i.d., levopromazine $100 \mathrm{mg}$ t. i. d., valproate 500 $\mathrm{mg}$ b.i.d, clonazepam $5 \mathrm{mg}$ t.i.d. Her weight was 65 $\mathrm{Kg}$, height $153 \mathrm{~cm}$, body mass index (BMI) $27 \mathrm{Kg} / \mathrm{m}^{2}$, she had proximal muscle weakness, diffuse bone tenderness and antalgic gait.

Laboratory values at presentation and during follow up are summarized in table 1. A DXA scan was performed in March 2010 and showed a BMD of 0.459 $\mathrm{g} / \mathrm{cm}^{2}$ (Z-score -3.3 ) at the $\mathrm{L}_{2}-\mathrm{L}_{4}$ level of the spine and of $0.549 \mathrm{~g} / \mathrm{cm}^{2}$ (Z-score -2.1) at the femoral neck. The whole body ${ }^{99 \mathrm{~m}} \mathrm{Tc}$-methylene diphosphonate $\left({ }^{99 \mathrm{~m}} \mathrm{Tc}\right.$ MDP) bone scintigraphy showed an increased uptake at the lumbar and thoracic spine, sacroiliac region and hip joints, consistent with multiple pseudo-fractures (figure 1, panel A). The dorsal and lumbosacral spine $\mathrm{X}$-ray showed diffuse osteopenia, fracture deformities of D7and L2-L4 (Figure 2). Because of the temporal relationship between the beginning of TDF therapy and OM-related symptoms, in the absence of other explanations and in accord with previously published similar cases, ${ }^{4,13}$ we made a diagnosis of hypophosphatemic TDF-induced OM. TDF was stopped and the ART modified to darunavir boosted by ritonavir, emitricitabine and raltegravir. In addition, oral cholecalciferol (300,000 IU/daily for 2 days and $10,000 \mathrm{IU} /$ week $)$, calcitriol ( $0.25 \mathrm{mcg} /$ daily) and neutral sodium-potassium phosphate containing 1500 mg of phosphorus/daily were given. Two months after discontinuation of TDF, bone pain and gait disturbances as well as laboratory data were significantly improved (Table 1). Eleven months later, the patient was free of bone and joint-related symptoms and a whole body ${ }^{99 \mathrm{~m}} \mathrm{Tc}-\mathrm{MDP}$ bone scintigraphy showed complete resolution of the OM (Figure 1, Panel B).

Discussion. In the last 10 years, the life expectancy of adults with HIV infection has increased; the care of HIV-infected individuals has evolved from management of opportunistic infections to prevention and treatment of the metabolic complications of ART, including osteoporosis. HIV and/or ART-related bone damage coupled with the bone loss characteristic of older age could lead to a serious health threat. Bone loss, in fact, has been reported to be an accelerated event during ART, especially within the first 6 months of therapy. ${ }^{14}$ The SMART (Strategies for Management of Antiretroviral Therapy) Study has shown that ART may be associated with a $6 \%$ decrease in BMD during the first 2 years regardless of the drug combination used. ${ }^{14}$ Therefore, osteopenia, osteoporosis, and even, albeit rarely, osteomalacia, with a consequent increased risk of fracture are major adverse effects of ART, especially in a regimen including TDF. ${ }^{15}$ TDF dosedependent kidney toxicity, generally occurring within the first 4-12 months, is well known. In a recent metaanalysis, ${ }^{16}$ a significant loss of $3.92 \mathrm{~mL} / \mathrm{min}$ of estimated glomerular filtration rate (eGFR) has been 
Table 1. Laboratory investigations at presentation and during follow-up.

\begin{tabular}{|c|c|c|c|c|}
\hline Laboratory tests & $\begin{array}{l}\text { At presentation } \\
\text { (during TDF } \\
\text { therapy) }\end{array}$ & $\begin{array}{l}\text { Two months after the } \\
\text { TDF discontinuation }\end{array}$ & $\begin{array}{l}\text { Eleven months } \\
\text { after the TDF } \\
\text { discontinuation }\end{array}$ & Normal range \\
\hline Phosphate (mg/dL) & 1.5 & 4.2 & 3.5 & $2.5-5.0$ \\
\hline Calcium (mg/dL) & 8.9 & 9.6 & 9.6 & $8.5-10.7$ \\
\hline Alkaline phosphatase (IU/L) & 1356 & 678 & 191 & $80-320$ \\
\hline$\gamma$-glutamyltranspeptidase (UI/L) & 235 & 162 & 159 & $7-49$ \\
\hline 25-OH vitamin $\mathrm{D}(\mathrm{ng} / \mathrm{mL})$ & 5 & 39 & & $\begin{array}{c}\text { optimal concentration: } \\
>30 \mathrm{ng} / \mathrm{mL}\end{array}$ \\
\hline Parathyroid Hormone (ng/L) & 47 & & & $12-72$ \\
\hline Creatinine $(\mathrm{mg} / \mathrm{dL})$ & 0.99 & 0.92 & 0.87 & $0.5-1.4$ \\
\hline eGFR $*(\mathrm{~mL} / \mathrm{min} / 1.73 \mathrm{~m})$ & 64 & 70 & 75 & \\
\hline Urinary calcium (mg/24h) & 102 & & & $100-300$ \\
\hline Urinary phosphorus $(\mathrm{g} / 24 \mathrm{~h})$ & 0.38 & & & $0.3-1.0$ \\
\hline
\end{tabular}

reported with TDF use. Although mild, such reduction might become important in patients with prior underlying renal diseases, with potential nephrotoxic medications or comorbidities. Moreover, renal toxicity could be underestimated if evaluated as GFR alone rather than PRT toxicity. The PRT may result in phosphate wasting only or may progress to complete proximal tubular damage (De Toni-Debré-Fanconi syndrome), with impaired reabsorption and urine wasting of phosphate, calcium, magnesium, potassium, sodium, urate, amino acids, glucose and bicarbonate, resulting in hypophosphatemic $\mathrm{OM}$ and metabolic acidosis. Although the relative risk of grade 3-4 of hypophosphatemia has been reported to be low, ${ }^{16} \mathrm{TDF}$ dose adjustments are required in chronic renal diseases with eGFR lower than $50 \mathrm{~mL} / \mathrm{min}$, to avoid TDF accumulation and further renal injury. The proximal tubule is most commonly affected because it is a major site for the excretion of xenobiotics. However, the mechanism of TDF nephrotoxicity is not well understood. Mitochondrial damage and alterations in human organic anion transporter 1 have been suggested..$^{20}$ Proximal tubule mitochondrial injury, in part due to decreasing mitochondrial DNA replication through inhibition of mitochondrial DNA polymerase, would impair molecular transport, vitamin D activation, and urinary acidification. ${ }^{8}$ An increased risk of renal damage has been reported with TDF given with ritonavir-boosted protease inhibitors. ${ }^{18,19}$ Specifically, co-administration of TDF with atazanavir/ritonavir resulted in increases of TDF serum concentrations. Thus, patients who were receiving both ritonavir and atazanavir should be carefully monitored for an increase in TDF-associated adverse effects. ${ }^{20}$ Other factors that may increase TDF nephrotoxicity include a low BMI and the concomitant use of nonsteroidal antiinflammatory drugs. The rapid withdrawal of the drug usually reverses the renal damage, but a permanent De Toni-Debré-Fanconi syndrome may ensue. The link between kidney and bone toxicity of TDF is obvious, since hypophosphatemia may cause an inadequate mineralization of the bone matrix, with subsequent rickets or OM.

In the patient reported here the symptoms, the laboratory abnormalities (increased ALP activity, phosphate wasting with persistently low serum phosphate) and the imaging data (multiple ribs pseudofractures and vertebral fractures) led us to diagnose hypophosphatemic OM due to TDF toxicity, even without bone histomorphometry. The hypovitaminosis D could have partially contributed to OM. The normal PTH level which may seem peculiar in the presence of vitamin $\mathrm{D}$ deficiency, might be related to a negative feedback of hypophosphatemia on the parathyroid glands, being phosphate an important regulator of $\mathrm{PTH}^{21}$ The normal level of PTH, in the setting of hypovitaminosis $\mathrm{D}$, associated with hypophosphatemia was consistent with hypophosphatemia as the prevalent metabolic alteration in our patient. The dramatic clinical and laboratory improvements observed with the discontinuation of the drug confirmed the diagnosis of OM. The presence of liver and psychiatric disorders and the complex drug regimens could have significantly contributed to the increased risk of fractures since a low BMD has been linked to borderline personality disorders. ${ }^{22}$ Of particular concern from a clinical point of view is that pseudofractures in $\mathrm{OM}$ can be misdiagnosed as disseminated bone malignancy, because the whole body scintigraphy, in the late stage of OM, such in our case, shows a bone pattern of diffuse or focal tracer's uptake, that is similar to bone metastases. In conclusion, adverse effects, virtually found with all antiretroviral drugs, are the major cause for the switching or discontinuation of the therapy and for poor medication adherence. Although bone damage is common in HIV patients, alternative causes, including drug toxicity, must be searched because often can be easily treated. In particular, clinicians should be aware of TDF induced-OM, especially in patients with relevant co-morbidities and complex therapy. In 
patients treated with TDF, a monitoring of serum phosphorus, creatinine and ALP could be performed according to the European AIDS Clinical Society (EACS) guidelines, ${ }^{23}$ and a pre-treatment dosage and implementation of vitamin $\mathrm{D}$, may be convenient. If hypophosphatemic $\mathrm{OM}$ is suspected, a rapid discontinuation of the medication is necessary to

\section{References:}

1. Jacobson DL, Spiegelman D, Knox TK, Wilson IB. Evolution and predictors of change in total bone mineral density over time in HIV-infected men and women in the nutrition for healthy living study. J Acquir Immune Defic Syndr. 2008;49: 298-308. http://dx.doi.org/10.1097/QAI.0b013e3181893e8e PMid:18845956

2. Mazzotta E, Agostinone A, Rosso R, Di Biagio A, De Socio GV, Cappelletti A, Zicolella R, Polilli E, Bonfanti P, Di Matteo L, Manzoli L, Parruti G. Osteonecrosis in human immunodeficiency virus (HIV)-infected patients: a multicentric case-control study. J Bone Miner Metab. 2011;29:383-388. http://dx.doi.org/10.1007/s00774-010-0245-5 PMid:21258827

3. Parsonage MJ, Wilkins EG, Snowden N, Issa BG, Savage MW. The development of hypophosphataemic osteomalacia with myopathy in two patients with HIV infection receiving tenofovir therapy.HIV Med. 2005; 6:341-6. http://dx.doi.org/10.1111/j.14681293.2005.00318.x PMid:16156882

4. Di Biagio A, Rosso R, Monteforte P, Russo R, Rovetta G, Viscoli C. Whole body bone scintigraphy in tenofovir-related osteomalacia: a case report. J Med Case Reports. 2009; 3:8136. http://dx.doi.org/10.4076/1752-1947-3-8136 PMid:19830218 PMCid:2737799

5. Horberg M, Tang B, Towner W, Silverberg M, Bersoff-Matcha S, Hurley L, Chang J, Blank J, Quesenberry C Jr, Klein D. Impact of tenofovir on renal function in HIV-infected, antiretroviral-naive patients. J Acquir Immune Defic Syndr. 2010; 53:62-9. http://dx.doi.org/10.1097/QAI.0b013e3181be6be2 PMid:19838127

6. Malik A, Abraham P, Malik N. Acute renal failure and Fanconi syndrome in an AIDS patient on tenofovir treatment--case report and review of literature. $J$ Infect. 2005;51: E61-5. http://dx.doi.org/10.1016/j.jinf.2004.08.031 PMid:16038754

7. Woodward CL, Hall AM, Williams IG, Madge S, Copas A, Nair D, Edwards SG, Johnson MA, Connolly JO. Tenofovir-associated renal and bone toxicity. HIV Med. 2009;10:482-7 http://dx.doi.org/10.1111/j.1468-1293.2009.00716.x PMid:19459988

8. Fernandez-Fernandez B, Montoya-Ferrer A, Sanz AB, SanchezNiño MD, Izquierdo MC, Poveda J, Sainz-Prestel V, Ortiz-Martin N, Parra-Rodriguez A, Selgas R, Ruiz-Ortega M, Egido J, Ortiz A. Tenofovir nephrotoxicity: 2011 update. AIDS Res Treat. 2011;2011:354-908.

9. De Socio GV, Ricci E, Parruti G, Maggi P, Madeddu G, Quirino T, Bonfanti P. Chronological and biological age in HIV infection. J Infect. 2010;61:428-30. http://dx.doi.org/10.1016/j.jinf.2010.09.001 PMid:20833202

10. De Socio GV. Schizophrenia, drug therapy, and monitoring. N Engl J Med. 2004;350:415-6. http://dx.doi.org/10.1056/NEJM200401223500420

11. De Socio GVL, Fanelli L, Longo A, Stagni G Adherence to antiretroviral therapy in HIV patients with psychiatric comorbidity. J Acquir Immune Defic Syndr 2004; 36:1109-1110 . PMid 15247568

12. Madeddu G, Bonfanti P, De Socio GV, Carradori S, Grosso C, prevent a permanent renal damage, moreover phosphate, calcitriol and cholecalciferol administration seems to be useful to accelerate recovery from the disease.

Acknowledgement. We thanks Ms Iraci Jacqueline for the review of the English translation.
Marconi P, Penco G, Rosella E, Miccolis S, Melzi S, Mura MS, Landonio S, Ricci E, Quirino T; CISAI Group. Tenofovir renal safety in HIV-infected patients: results from the SCOLTA Project. Biomed Pharmacother. 2008;62:6-11. http://dx.doi.org/10.1016/j.biopha.2007.04.008

13. Jhaveri MA, Mawad HW, Thornton AC, Mullen NW, Greenberg RN. Tenofovir-associated severe bone pain: I cannot walk! J Int Assoc Physicians AIDS Care (Chic). 2010;9:328-34. http://dx.doi.org/10.1177/1545109710376595 PMid:20923957

14. Grund B, Peng G, Gibert CL, Hoy JF, Isaksson RL, Shlay JC, Martinez E, Reiss P, Visnegarwala F, Carr AD; INSIGHT SMART Body Composition Substudy Group. Continuous antiretroviral therapy decreases bone mineral density. AIDS. 2009;23:1519-29. http://dx.doi.org/10.1097/QAD.0b013e32832c1792 PMid:19531929 PMCid:2748675

15. Fabbriciani G, De Socio GV, Massarotti M. Antiretroviral therapy and adverse skeletal effects. Mayo Clin Proc. 2011;86:916-7. http://dx.doi.org/10.4065/mcp.2011.0341 PMCid:3257996

16. Cooper RD, Wiebe N, Smith N, Keiser P, Naicker S, Tonelli M. Systematic review and meta-analysis: renal safety of tenofovir disoproxil fumarate in HIV-infected patients. Clin Infect Dis. 2010 1;51:496-505. http://dx.doi.org/10.1086/655681 PMid:20673002

17. Créput C, Gonzalez-Canali G, Hill G, Piketty C, Kazatchkine M, Nochy D. Renal lesions in HIV-1-positive patient treated with tenofovir. AIDS. 2003 11;17:935-7

18. Goicoechea M, Liu S, Best B, Sun S, Jain S, Kemper C, Witt M, Diamond C, Haubrich R, Louie S; California Collaborative Treatment Group 578 Team. Greater tenofovir-associated renal function decline with protease inhibitor-based versus nonnucleoside reverse-transcriptase inhibitor-based therapy. J Infect Dis. 2008;197:102-8 http://dx.doi.org/10.1086/524061 PMid:18171292

19. Zimmermann AE, Pizzoferrato T, Bedford J, Morris A, Hoffman $R$, Braden G. Tenofovir-associated acute and chronic kidney disease: a case of multiple drug interactions. Clin Infect Dis. 2006;42:283-90. $\quad$ http://dx.doi.org/10.1086/499048 PMid: 16355343

20. Madeddu G, Quirino T, Carradori S, Ricci E, Grosso C, Penco G, De Socio G, Rossella E, Palvarini L, Marconi P, Melzi S, Mura MS, Bonfanti P; Gruppo CISAI. Renal toxicity in HIV-infected patients receiving HAART including tenofovir. Infez Med. 2006;14:125-34. PMid:17127826

21. Hirotaka Komaba, Takatoshi Kakuta, Masafumi Fukagawa, Diseases of the parathyroid gland in chronic kidney disease, Clin Exp Nephrol 2011;15:797-809. http://dx.doi.org/10.1007/s10157011-0502-5 PMid:21818548

22. De Socio GV, Fabbriciani G, Fanelli L, Leli C, Callarelli L, Scarponi AM. Low bone mineral density in institutionalized patients with HIV and psychiatric co-morbidity. Infez Med. 2008;16:86-90. PMid:18622148

23. European AIDS Clinical Society. Web site.http://www.europeanaidsclinicalsociety.org/guidelines/g2.htm Accessed November, 2011. 